\title{
EL CEMENTO ALUMINOSO Y EL TURÓ DE LA PEIRA DE BARCELONA
}

\author{
(THE HIGH ALUMINA CEMENT AND EL TURO DE LA PEIRA OF BARCELONA)
}

Víctor Seguí Santana, Dr. Arquitecto ESPAÑA

Fecha de recepción: 11-XI-92

RESUMEN

En el presente artículo se expone el proceso y la metodología utilizada para la confección del informe "Análisis del estado actual del soporte estructural de las viviendas del Turó de la Peira" y del proyecto de "Reparación / Consolidación de las fincas 31, 33, 35 de la Cl. Cadi" de dicho barrio, así como los resultados generales del Informe y la propuesta de Reparación.

\section{SUMMARY}

This article explains the process and the methodology used to make the report "Analysis of the present state of the structure of dwellings in Turó de la Peira" and of the project "Repair / Consolidation of estates $31,33,35$ of the Cadi Street" of the same residential block. It also offers the general results of the Report and the Repair proposal.

\section{INTRODUCCIÓN}

La existencia de cemento aluminoso, de comportamiento desconocido por el usuario en la composición de las viguetas de los techos de la finca ubicada en la C/. Cadí, 33, que presentó un hundimiento parcial el 11.11.90, con el resultado fatal de la pérdida de una vida humana, desencadenó una importante alarma social en la ciudad que motivó la formación de la Comisión del Turó de la Peira. Comisión en la que estuvieron representados: la Generalitat de Catalunya, El Ayuntamiento de Barcelona, La Inmobiliaria Sanahuja y Entidades Vecinales.

Esta Comisión generó otra comisión técnica más amplia que fijó, entre otros, los siguientes objetivos:

"Redacción de un informe e inspección del estado ac(c) Consejo Superior de Investigaciones Científicas Licencia Creative Commons 3.0 España (by-nc) tual de la edificación general del barrio del Turó de la Peira con el asesoramiento de la O.C.T. del Col. legi d'Aquitectes de Catalunya y el apoyo en el trabajo de campo del Institut de Tecnología de la Construcció de Catalunya" (ITEC).

"Redacción de un proyecto de reparación y consolidación inmediata de las escaleras en la C/. Cadí, 31, 33 y $35 "$ ".

Los objetivos pormenorizados del informe, propuesta técnica para la consolidación, composición del equipo técnico y metodología del trabajo fueron aprobados el 14.12.90 en el seno de dicha comisión.

El mencionado informe y el proyecto de reparación/ consolidación, fueron entregados el 20 de marzo 1991. http://informesdelaconstruccion.revistas.csic.es 


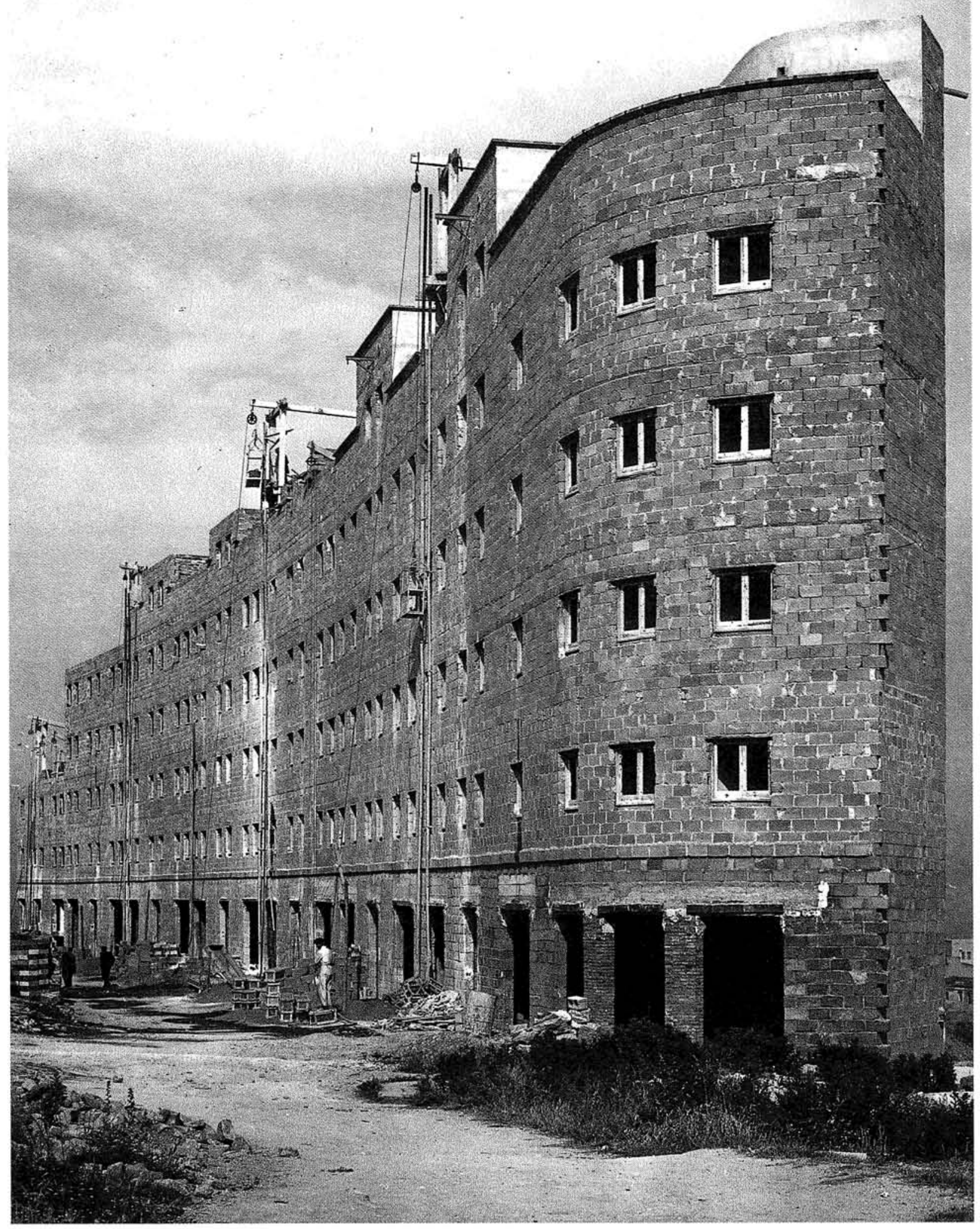

Edificio de la calle Cadi en construcción, en el que se observan los métodos y materiales empleados. 


\section{CARACTERÍSTICAS URBANÍSTICAS}

La zona objeto del estudio está incluida en el Plan Parcial del Turó de la Peira, aprobado el 23.1.59 por la Comisión de Urbanismo, quedando recogido en el Plan General Metropolitano con la calificación "Zona sujeta a Ordenación Volumétrica específica (18)".

La primera petición de permiso de obras se recibe en el Ayuntamiento el 21.1.1954, una vez aprobado el Plan Comarcal (31.12.53), basándose en un proyecto de alineaciones y rasantes de mayo del 53 .

Posteriormente, y antes de la aprobación del Plan Parcial del Sector, se realizan nuevos proyectos de alineaciones y rasantes en los que se recorta el Parque del Turó dando lugar a más suelo edificable que sería utilizado en las fases finales del proceso inmobiliario.

Como referencia a la antigüedad de la construcción y su relación con el planeamiento cabe mencionar que los certificados finales de obra se comenzaron a emitir el 14.4.55 hasta el 10.11.61. De donde se deduce inmediatamente que únicamente algunas manzanas fueron certificadas una vez aprobado el Plan Parcial, de tal manera que en la mayoría de los casos el planeamiento recoge la realidad construida y no la previsión futura.

El Turó de la Peira es un barrio dénsamente edificado con dos tipos de manzana claramente diferenciados: cerrada, correspondiente a las actuaciones anteriores a la aprobación del Plan Parcial y abierta, en las posteriores.

El tamaño de la manzana cerrada es pequeño, con un patio de manzana residual una vez aplicada la profundidad edificable y con problemas graves de ventilación en las esquinas.

Las pendientes de las calles perpendiculares a las curvas de nivel dan secciones edificatorias con un primer, un segundo $\mathrm{y}$, en algún punto, hasta un tercer sótano.

En cuanto a la altura edificable, el número de plantas típicas es $\mathrm{PB}+4$ ó $\mathrm{PB}+7$, según las zonas.

\section{DESCRIPCIÓN GENERAL DE LA EDIFICACIÓN}

El tipo que genera toda la edificación es el de agrupación en altura con acceso puntual a 4 viviendas, que se utiliza tanto para resolver la manzana cerrada, solucionando las esquinas en su caso, como para la manzana abierta.

La organización en planta es típica con dos viviendas a la calle y dos al patio de manzana o posteriores, resolviendo la ventilación de las piezas interiores mediante patios de luces. En planta baja la franja a la calle convierte su uso en comercial, manteniendo la interior con uso residencial.

La vivienda típica se compone de: recibidor, paso distribuidor, cocina, lavadero, aseo, tres dormitorios y comedor, con una superficie útil de $50 \mathrm{~m}^{2}$ aproximadamente en las manzanas cerradas y de $60 \mathrm{~m}^{2}$ en las manzanas abiertas.

Se han contabilizado 4.044 viviendas con 54 tiendas reconvertidas, que arrojan un total de 4.098 viviendas.

La proporción de viviendas en planta baja y sótanos mas las que tienen luces rectas menores de $3 \mathrm{~m}$ es del $14 \%$ (580/4098). Y la proporción de áticos y sobreáticos es del $9 \%(363 / 4098)$.

Datos de superficie útil y situación, previos e indispensables, ante el dimensionado de cualquier operación de renovación urbana.

\section{DESCRIPCIÓN CONSTRUCTIVA}

Cimientos corridos de hormigón en masa.

Estructura portante de muros de carga, independientemente de la altura de los edificios. Estos muros se disponen paralelos a la fachada a una distancia de $3,5 \mathrm{~m}$ aproximadamente.

La edificación se organiza en dos franjas, una a la calle y otra posterior con tres muros de carga cada una. 


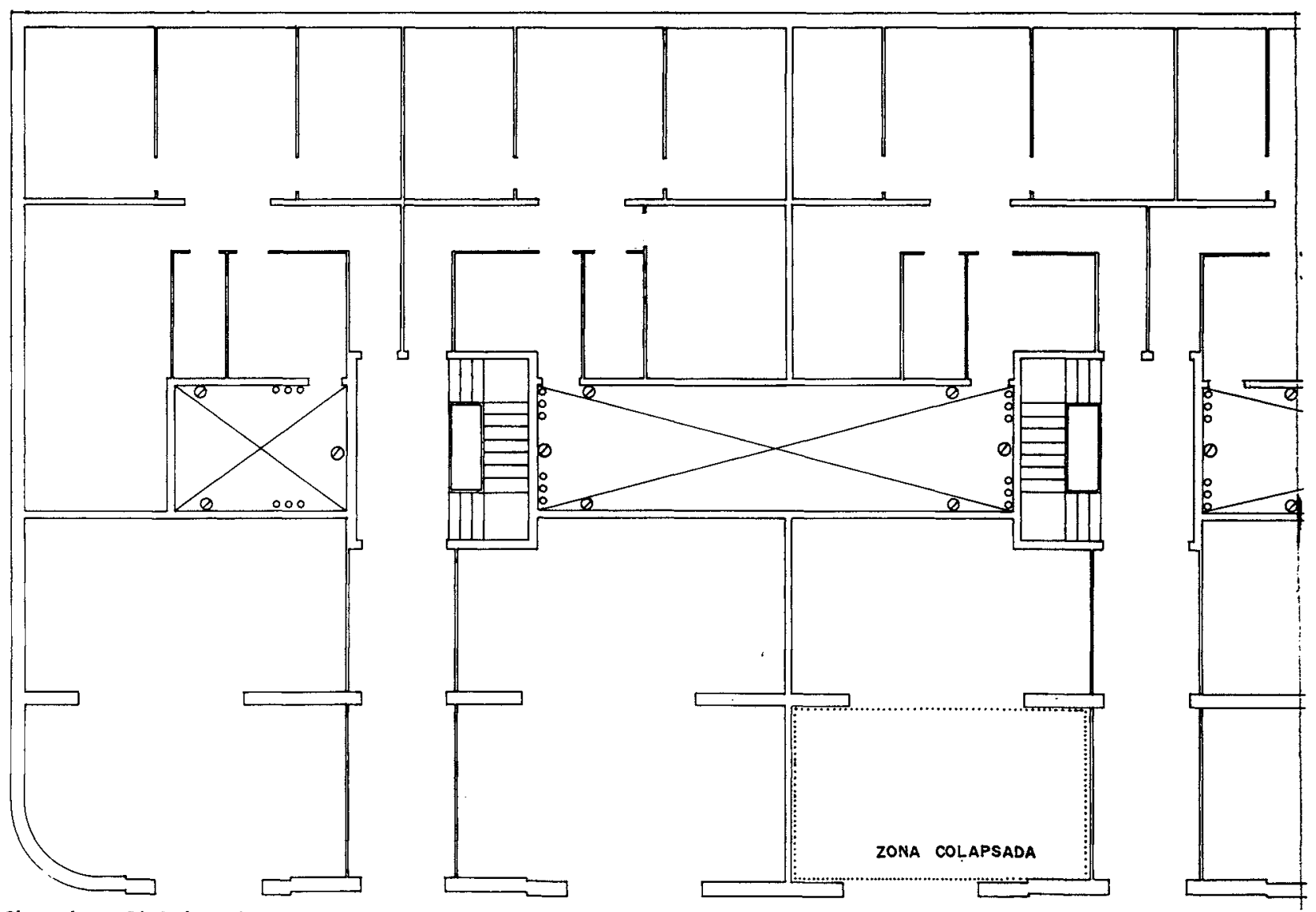

Planta baja. C/. Cadí, 31/33.

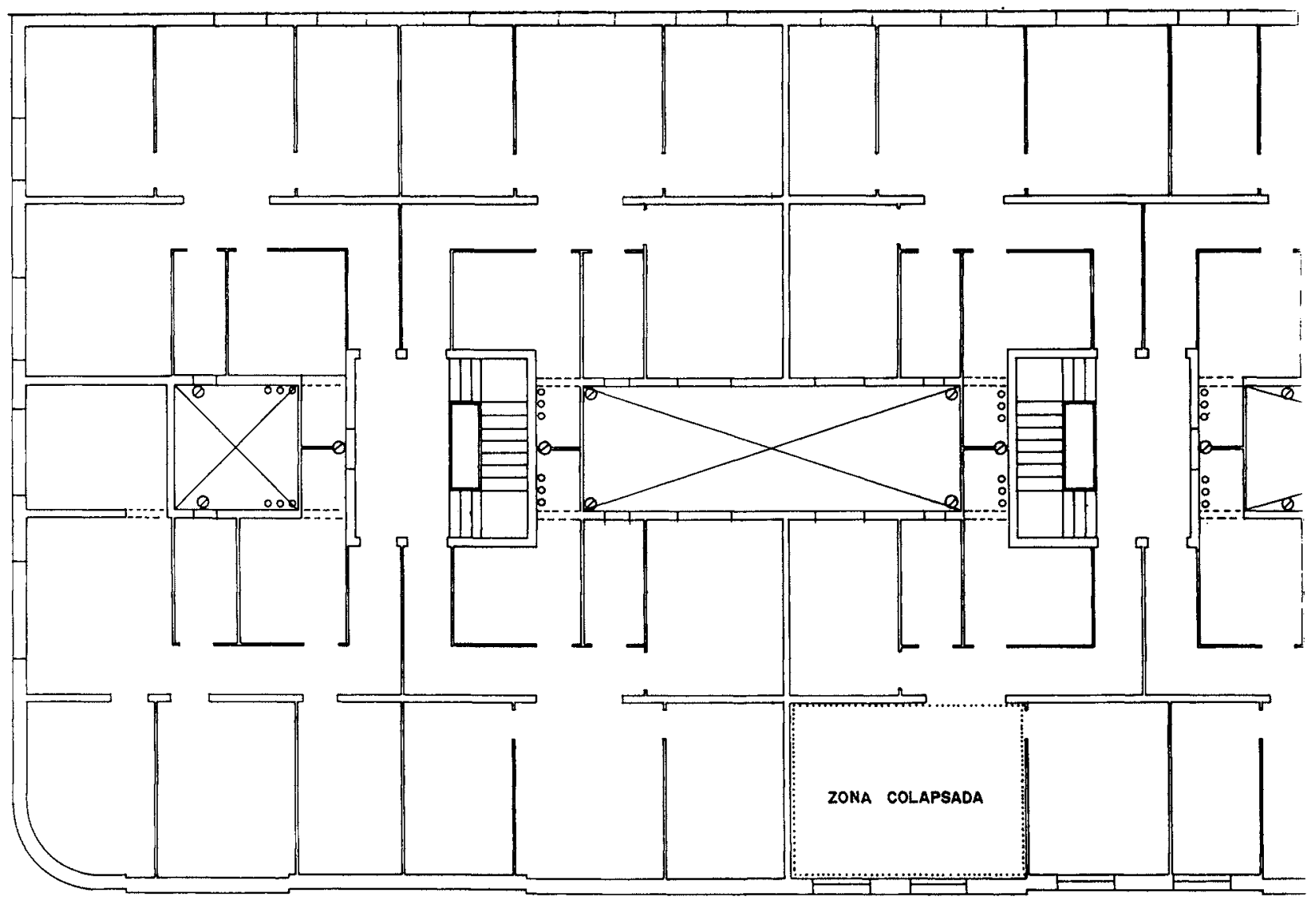

Planta tipo. Cl. Cadi, 31/33. 


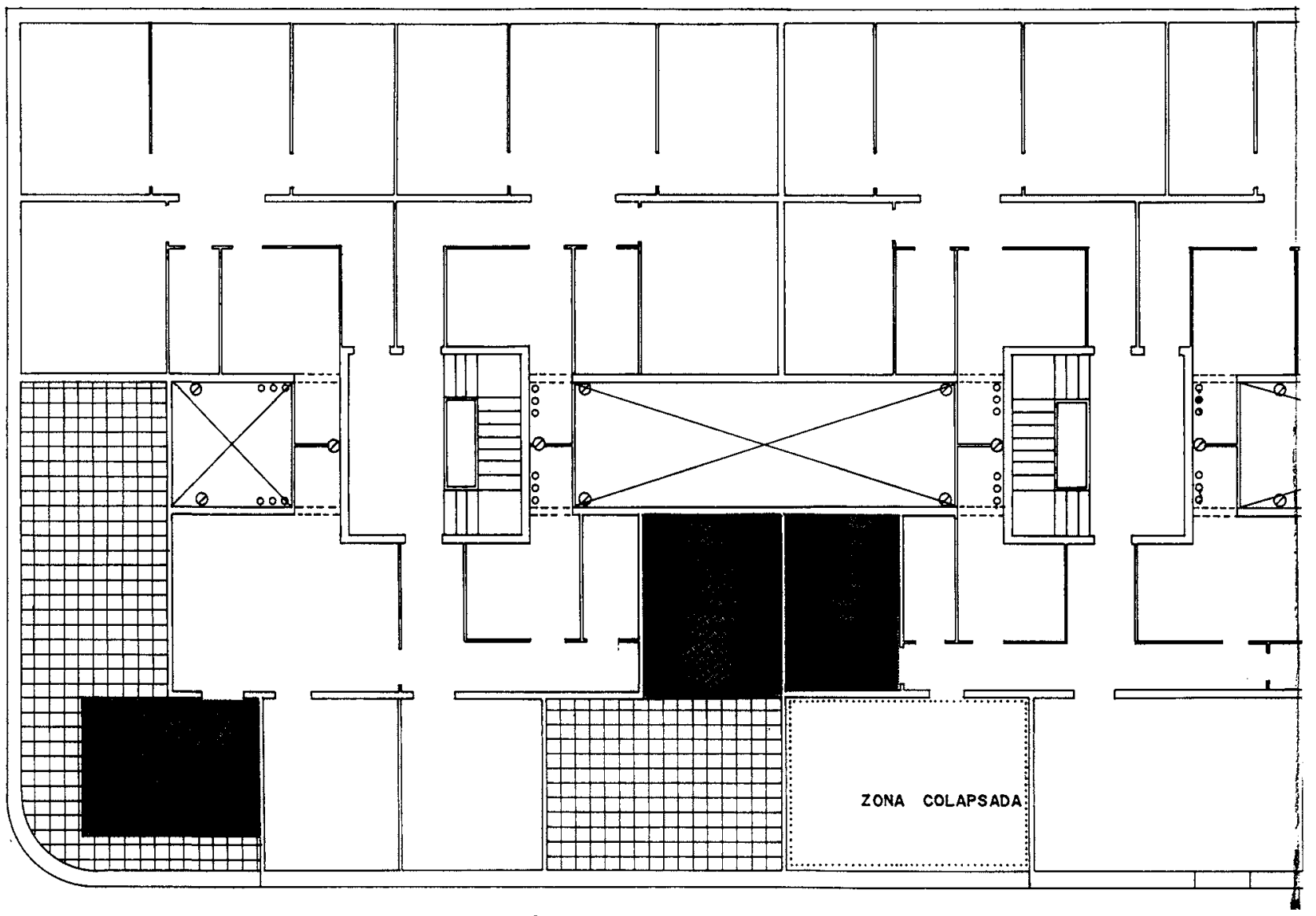

Planta ático. C/. Cadí, 31/33.

El arriostramiento del conjunto se consigue con los muros de trabazón (separadores de fincas) y el núcleo de la escalera.

Los materiales utilizados fueron: el ladrillo macizo, el ladrillo hueco y el bloque de hormigón -relleno o no de hormigón- $\mathrm{y}$ los morteros de cal, cemento portland y cemento lento y sus mezclas.

Los techos construidos con viguetas autorresistentes de hormigón armado o de cerámica armada entrevigado con revoltón forjado en obra o prefabricado, incluso solera de machihembrado cerámico.
Cubierta a la catalana.

Suelo de la planta baja realizado sobre solera.

Escalera a la catalana.

Revestimientos interiores en yeso y cielorasos en los techos con revoltón forjados en obra. Exteriores con mortero de cal.

Saneamiento general realizado con tubos cerámicos.

Fontanería ejecutada con tubería de plomo y Electricidad bajo tubo bergmann. 

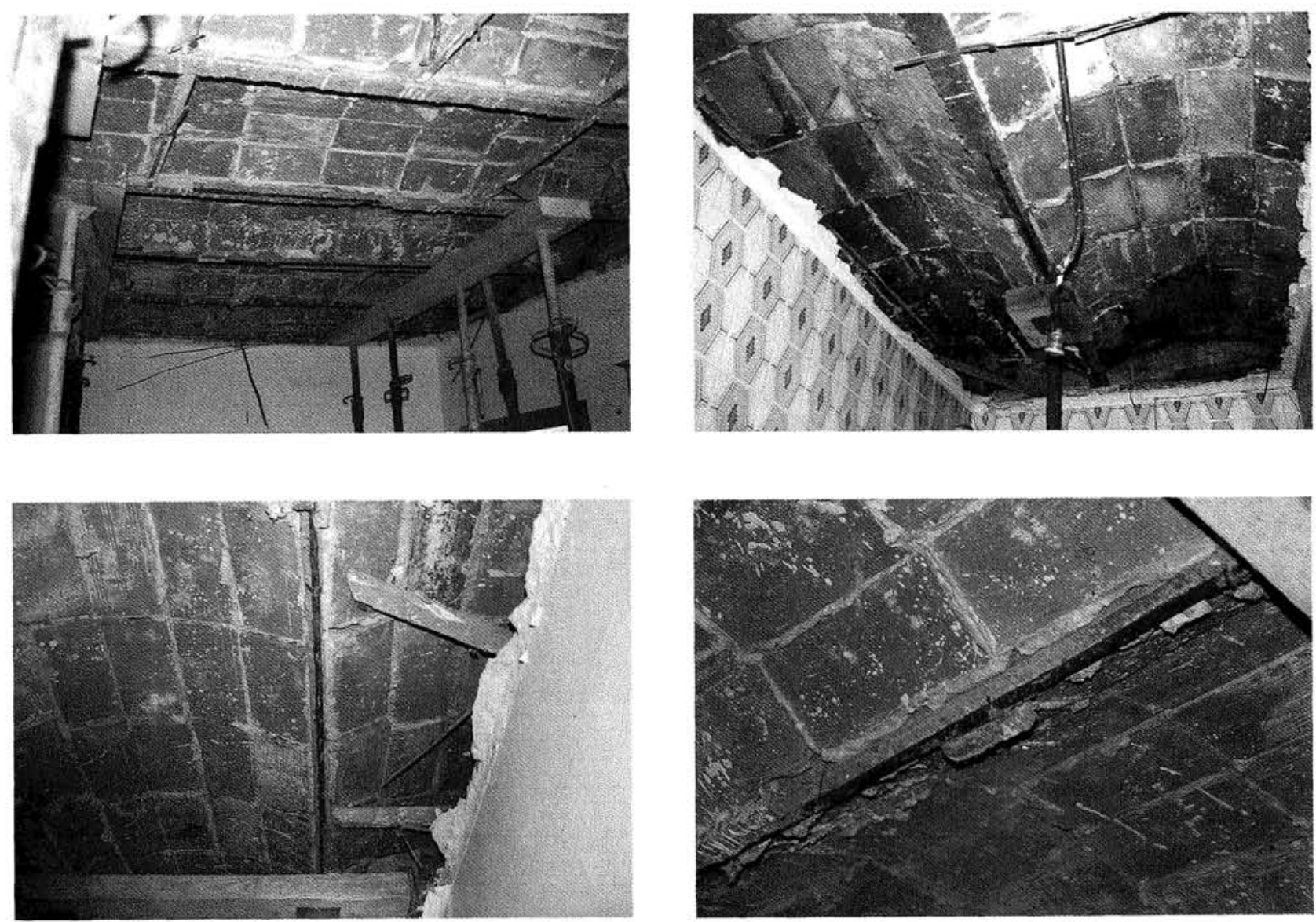

Estado de algunas de las viguetas. Cl. Cadí, 33.

\section{METODOLOGÍA DEL INFORME}

El punto de partida "existencia de C.A. en las viguetas" y los objetivos "estado de conservación del soporte estructural", así como el volumen del barrio y el tiempo disponible, motivó que la recogida de información persiguiera los siguientes aspectos:

1) Adecuación de la cimentación a las cargas que soporta y al terreno.

2) Determinación de la composición de los muros estructurales.

3) Estado de los forjados.

4) Determinación de la existencia de cemento aluminoso.
5) Protección de humedades.

1) Se centra en dos aspectos: recogida de información geotécnica, de tipo general correspondiente a la zona, complementaria con los sondeos necesarios para el proyecto de Cadi, 31, 33 y 35, así como indicios que se desprenden de los informes de los arquitectos autores de la obra.

Realización de un levantamiento de todas las fachadas con reportaje fotográfico, en el que se ponen de manifiesto las grietas y fisuras.

Dado que las fachadas son de carga, una revisión de las mismas, si bien no representa un conocimiento exhaustivo del comportamiento de los muros respecto del terreno, sí que es una buena aproximación con facilidad de lectura y recogida de información. 
2) Para la determinación de la composición de los muros de carga se ha realizado un muestreo mediante una encuesta a ciertas fincas de cada manzana definiendo materiales y espesores.

3) Para conseguir un conocimiento razonable del estado de los techos, el ITEC ha efectuado un muestreo de los forjados de las viviendas.

Se han llevado a cabo inspecciones a las plantas, bajo cubierta, tipo, baja y sótano.

En cada vivienda inspeccionada se han realizado 3 ó 5 catas (baño, cocina, galerías, 2 en la sala de estar o dormitorio, locales húmedos, extremos de viguetas, o zonas neutras).

Aleatoriamente se realizaba la extracción de una muestra de material para su posterior análisis.

La inspección buscaba la existencia de lesiones. El encuestador clasificaba en 5 niveles, para más tarde fijar el nivel de intervención.

Complementariamente se recogían los datos referentes al tipo de forjado, y de la cubierta.

4) La analítica desarrollada por el laboratorio de la D.G. de Arquitectura i Habitatge, en general somete a las muestras a la determinación del contenido de alúmina mediante la prueba de absorción atómica. En algunos casos se realizó análisis químico.

Y por último, siempre que fue posible por el tamaño de las muestras, la determinación de porosidad. $\left(^{*}\right)$ $\left({ }^{* *}\right)$.

5) Recogida de las evidencias de posibles humedades de todo tipo.

(*) Todas las muestras fueron analizadas por el "pachómetro", con lo que se consiguió la primera clasificación referente a la existencia de C.A. Ver INFORMES DE LA CONSTRUCCIÓN n. 419.

(**) Se han efectuado roturas de vigas con resultados extremadamente bajos.
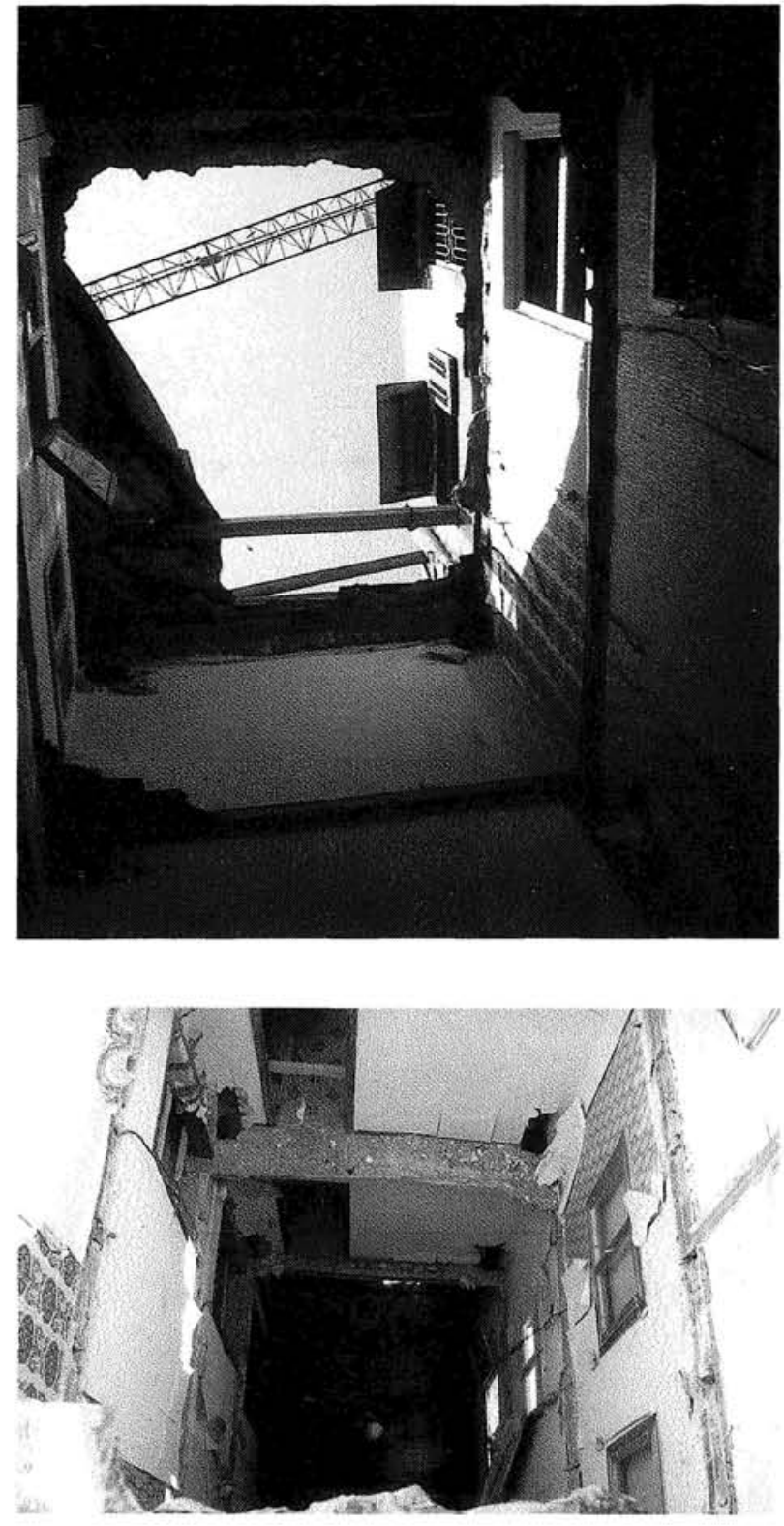

Hundimiento parcial. Cl. Cadi, 33.

\section{INFORME}

El proceso constructivo del barrio ha de inscribirse forzosamente en el mundo económico de aquel tiempo.

La ciudad de Barcelona, importante polo de atracción de las migraciones, se ve fuertemente impactada por esta realidad, con la necesidad perentoria de construir viviendas sociales en poco tiempo. Las Administraciones, tanto municipales como estatales, son incapaces de solventar el grueso de las necesidades dejando la solución de este problema en manos privadas. 

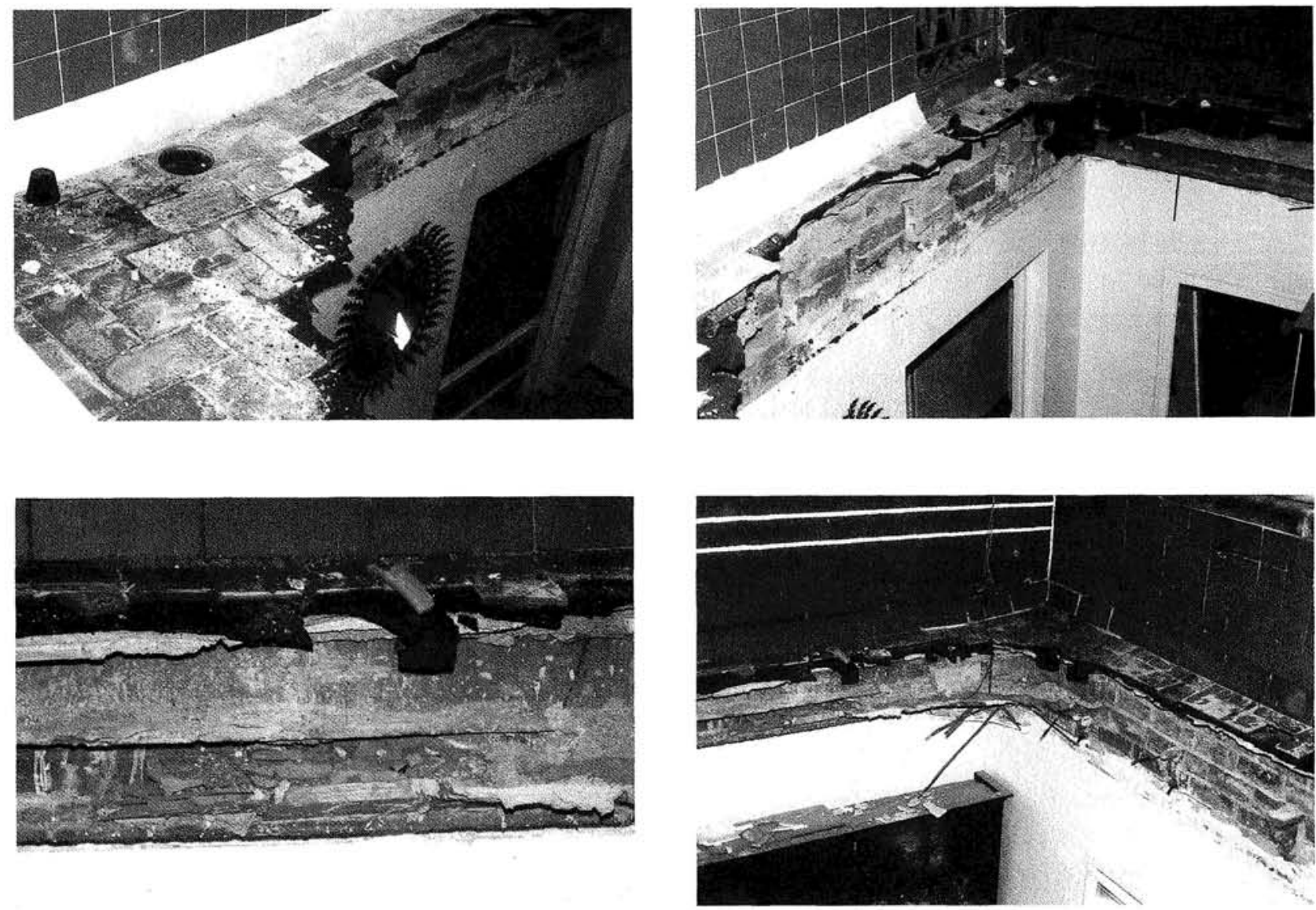

Secuencia fotográfica del contorno del suelo del ático. Cl. Cadí, 33.

Este "Boom" inmobiliario se encuentra, en la práctica, con la inexistencia de industria de la construcción y con escasez de acero y de cemento portland.

La Orden del 12 de julio de 1955, sobre viviendas de "Renta Limitada", reconocía la situación de hecho y limitaba el uso de acero por $\mathrm{m}^{2}$ de techo, potenciando indirectamente las piezas de hormigón precomprimido. Los fabricantes de viguetas no daban abasto a la demanda existente y necesitaban realizar fuertes inversiones para ampliar la industria o conseguir un cemento de fraguado rápido. Característica que "posee" el cemento aluminoso y que provoca su utilización masiva en la fabricación de viguetas.

En el Turó de la Peira, a pie de obra, se fabricaba todo lo que se necesitaba, como viguetas, bloques, etc. para cubrir las necesidades en cada momento, utilizando cemento portland, cemento aluminoso y otros.
Dado que las viviendas eran de tipo social, los materiales eran sencillos y muy aprovechados, y se colocaban en la obra muy rápidamente para permitir una rotación corta de las inversiones en equipo.

En líneas generales la utilización de los materiales fue la siguiente:

- Al principio, en las paredes estructurales se utilizaba la cerámica: En la planta baja ladrillo macizo y en el resto -cinco plantas como mínimo- ladrillo hueco. Los techos construidos con viguetas fabricadas a pie de obra con cemento aluminoso, con la ayuda de viguetas de cerámica armado cuando hacían falta, y revoltón de cerámica, forjado en obra o soleras de machihembrado cerámico.

- Al final del proceso constructivo, se utilizó básicamente el bloque de hormigón en las paredes estruchttp://informesdelaconstruccion.revistas.csic.es 
turales y techos, compuestos por viguetas de cemento portland y bovedilla prefabricada.

De todos modos, la construcción real siempre iba marcada por las existencias en los almacenes de la obra, dando heterogeneidad al conjunto.

El proceso de construcción se realizaba manzana a manzana levantando las paredes de carga longitudinales, las paredes medianeras entre fincas y, posteriormente, colocando los techos.

Treinta y cinco años después, nos encontramos con unas edificaciones en las que el mantenimiento ha sido mínimo o inexistente y en estado de conservación general deficiente, seguramente consecuencia del tipo de tenencia de la vivienda. Por lo tanto, toda opinión sobre el conjunto debe tener en cuenta esta carencia.

Una vez realizado el trabajo de campo y su posterior elaboración en gabinete, el informe global resultante puede resumirse en los siguientes apartados:

1.-Frente a un buen terreno para el tipo de cimentación empleado, en general, encontramos más evidencias de lesiones por motivos constructivos (influencia de la dilatación térmica y deformaciones diferenciales), que por falta de la adecuación del cimiento al terreno.

2.-Dos aspectos se evidencian èn el análisis de muros: su composición heterogénea y el agotamiento de la resistencia a compresión de las fábricas en algún punto.

3.-De la inspección realizada en los forjados se deducen un $61,9 \%$ de puntos sin lesiones, un $20,2 \%$ con lesiones de menor importancia y un $17,9 \%$ con lesiones graves. Se deben tener en cuenta las lesiones polarizadas en las manzanas antiguas.

4.-Existencia de C.A. evidenciada en el $43 \%$ de las muestras analizadas, ubicadas básicamente en las zonas iniciales de la construcción del Turó, asociada a la vigueta de ala estrecha prefabricada a pie de obra.

No se ha detectado C.A. en los bloques de hormigón.

La porosidad del hormigón en las viguetas confeccionadas con C.P. es alta, pero aceptable. Las de C.A. sobrepasan los límites aconsejables para la protección de armaduras.
5.-Existen numerosas evidencias de humedades de infiltración capilaridad, condensaciones y empapamientos.

Este informe global se descompone en un informe manzana a manzana con recomendaciones particularizadas, las cuales dado el alcance del presente artículo sería excesivamente prolijo comentarlas. Sin embargo, sí es interesante resaltar el alcance de las mismas que van desde la no recomendación de reparación/consolidación dado el estado de conservación del conjunto y sus características constructivas (manzanas A y B), hasta únicamente la de reparaciones puntuales donde haga falta (manzanas $\mathrm{L}, \mathrm{LL}$ ).

\section{CONSOLIDACIÓN/REPARACIÓN DE LAS FINCAS DE LA Cl. CADÍ, 31, 33 y 35 DE BARCELONA}

La memoria del proyecto contempla los trabajos necesarios de las fincas para conseguir el objetivo básico propuesto. Estos trabajos se han definido a partir de los siguientes criterios:

1) Devolver la seguridad de uso a los edificios.

2) Reparar los elementos constructivos que resulten afectados por los trabajos de consolidación.

3) Eliminar las acciones externas que aumentan la degradación de los materiales y reducen las condiciones de habitabilidad.

El primer criterio, restablecer la seguridad de uso; se asumirá en sentido estricto cuando se consoliden los techos de viguetas prefabricadas con cemento aluminoso. Esta consolidación está en sintonía con los acuerdos del 14 de diciembre de 1990 de la Comisión Técnica del Turó de la Peira. En sentido amplio, la seguridad se asume cuando, además, se eliminan las cornisas y molduras de fachada, que son un peligro potencial de caída al exterior.

Como criterios adicionales para definir el sistema de consolidación de los techos, deben considerarse:

- No afectar las fachadas y cerramientos exteriores de las viviendas.

- Limitar la pérdida de altura libre interior al mínimo posible.

- Limitar la destrucción de la compartimentación interior. 


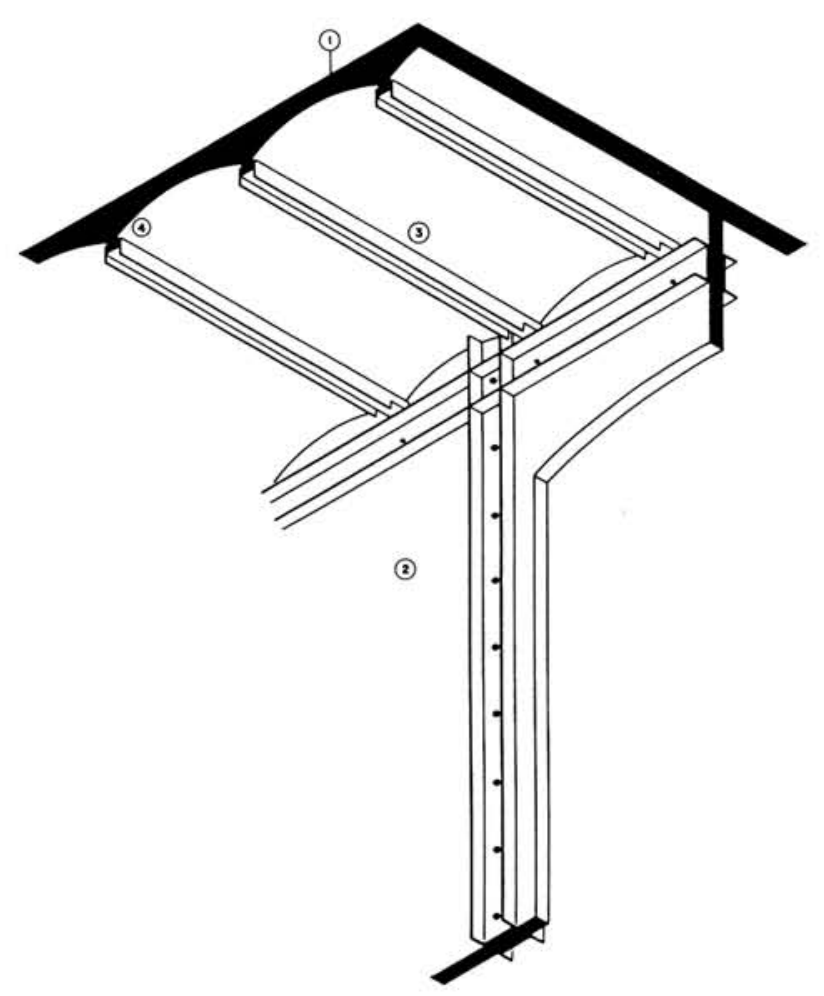

Propuesta de consolidación.

1.-Forjado existente construido con vigueta doble $\mathrm{T}$ de hormigón armado de cemento aluminoso y bovedilla forjada en obra.

2.-Paredes de carga existentes construidas con ladrillo doble hueco de $0,15 \mathrm{~m}$ de espesor y mortero mixto.

3.-Perfil HEB $100 \mathrm{~A}-52 \mathrm{~b}$ apoyado sobre perfiles UPN calzados con pletinas y puntos de soldadura.

4.-Mortero autonivelante inyectado previa imprimación de la vigueta con asfalto.

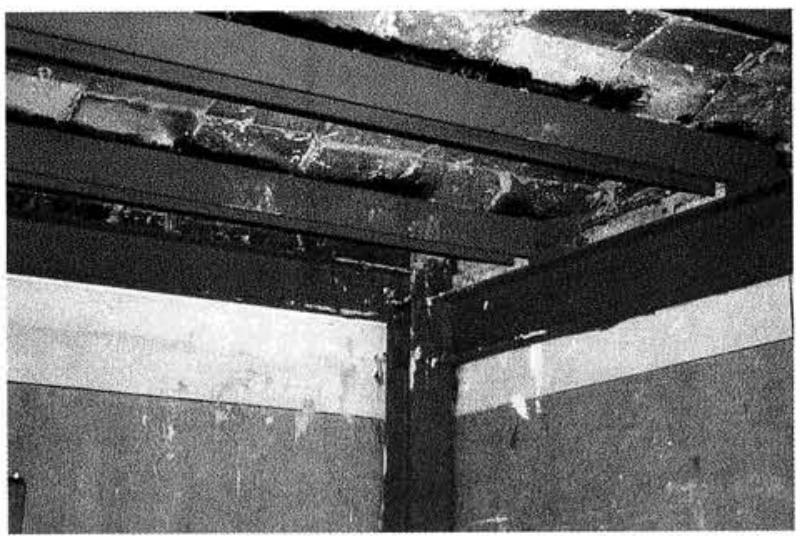

Aspecto de la consolidación efectuada.
- Reducir al mínimo indispensable las molestias de circulación de uso normal al interior de las viviendas.

- No añadir nuevas cargas, ni modificar su situación, sobre la estructura portante y cimentación existente.

Del estudio y profundización de las diversas posibles soluciones para conseguir una consolidación efectiva de la estructura, con los condicionantes antes mencionados, se ha derivado el sistema que se propone, que consiste en esquema el siguiente:

- Construcción de una estructura de barras con perfiles de acero laminado soldados en obra, autoportante, con capacidad para soportar la totalidad de las cargas gravitatorias aplicadas en los techos, como si de una obra de nueva planta se tratara. $\left(^{*}\right)$

- Construcción de cimientos para la nueva estructura, con zapatas de hormigón armado.

- Refuerzo de las viguetas actuales con un perfil de acero apoyado en la estructura de barras, asegurando el contacto entre las piezas antiguas y nuevas con mortero sin retracción autonivelante, previa pintura del ala inferior de la vigueta con asfalto para evitar interacciones de los dos tipos de morteros.

- Anclaje de los cerramientos de fachadas a la nueva estructtura, para garantizar su estabilidad si se reducen las cargas verticales.

El refuerzo de las viguetas con perfiles $\mathrm{H}$, con el alma horizontal, permite que sus alas formen una bandeja donde situar el mortero autonivelante y que la reducción de altura sea mínima: unos $10 \mathrm{~cm}$ contando la protección y el cielo raso de acabado.

Las piezas $\mathrm{H}$ de refuerzo se han dimensionado para resistir la totalidad de las cargas, sin colaboración de las viguetas de hormigón, con flechas limitadas que, en los peores casos, no sobrepasen el $1 / 350$ de la luz. $\left({ }^{* *}\right)$

(*) En la actualidad la Direcció General d'Arquitectura i Habitatge de la Consellería de Política Territorial i Obras Publiques de la Generalitat de Catalunya, está elaborando un protocolo de actuación frente a obras de reparación en el que se recoge el proceso a seguir, bases del dimensionado y alcance de la responsabilidad civil de los técnicos actuantes.

(**) Se han realizado pruebas de carga con viguetas de C.A. reforzadas con viguetas metálicas HEB 100 A.52b y relleno de mortero autonivelante con resultados altamente satisfactorios. http://informesdelaconstruccion.revistas.csic.es 
Donde ha sido posible, los pilares próximos a la fachada se sitúan en las esquinas de los locales o muy próximos a ellas para reducir la presencia de salientes a los paramentos interiores. La jácenas se sitúan en los encuentros techo-pared.

En los pilares de las crujías centrales se han previsto piezas cosidas a través del muro, que ofrece menos salientes en las zonas de paso. Este desdoblamiento, junto con el de sus jácenas constituye un arriostramiento de las paredes, que quedan abrazadas por ambas caras, aliviando la falta de encadenados con que fueron inicialmente construidos.

El arriostramiento de los muros de fachada, que tienen perfiles en un solo lado, se consigue mediante anclajes formados por trozos de perfiles L, soldados a las jácenas y empotrados a las paredes.

Los techos del sector colapsado de la casa n. 33 , se ha reconstruido con viguetas de acero, revoltones de hormigón y chapa de compresión armada, apoyados a la nueva estrutura.

La cimentación proyectada para la nueva estructura ha permitido no modificar el estado de tensiones actual de los cimientos.

La protección y acabado de los perfiles nuevos de acero se consigue mediante:

- Aplicación de protecciones contra corrosión, mediante pinturas.

- Construcción de cielo raso de plancha suspendida, tapando los perfiles de refuerzo de viguetas, de espesor suficiente para garantizar una resistencia al fuego RF90.

- Construcción de cajas de plancha de yeso envolviendo las barras verticales y horizontales de la estructura y sus protecciones, para regularización y soporte de acabados, de espesor suficiente para garantizar una resistencia al fuego RF90.
Una vez terminados estos trabajos, se realiza la reparación de elementos afectados, como: tabiques, instalación eléctrica interior, redes de fontanería y desagües, enyesados, carpintería, etc. Finalmente se procederá a pintar totalmente el interior de las viviendas.

Para eliminar las causas de degradación de materiales se deben suprimir las infiltraciones de aguas pluviales y las repetidas pérdidas de las redes de servicio. Con esta finalidad se prevé:

- Impermeabilización de las cubiertas con una lámina de butilo aplicada sobre los pavimentos actuales, previa regularización superficial protegida con una capa de rasilla cerámica colocada con material adecuado.

- Reconstrucción de los mimbeles a la nueva altura fijada por el pavimento con el sistema de caja ventilada hecha con rasilla cerámica.

- Substitución total de los colectores verticales de desagües y revisión de las conexiones con los sumideros de las azoteas, especialmente los tramos empotrados en los techos de los pisos altos.

- Substitución de los ramales verticales de agua hasta la llave de paso de la entrada de cada vivienda.

- Derribo de las cornisas y molduras, muy degradadas existentes en las fachadas, regularización de las superficies que ocupaban y protección de los salientes horizontales.

- Saneamiento del revoco de fachadas e impermeabilización general.

- Impermeabilización de las piezas de remate horizontal de los muretes de las cubiertas y barandillas de las terrazas de los áticos con imprimaciones de resinas, previo rellenado de juntas defectuosas con masilla de sellado.

En el momento de escribir estas líneas las obras de Reparación / Consolidación de las fincas de la C/. Cadí 31, 33 y 35 , están a punto de finalizar. 